\title{
Hard fats improve the physicochemical and thermal properties of seed fats for applications in confectionery products
}

\begin{abstract}
Hard fats, obtained from liquid oils by different fat modification techniques, are composed of highmelting-point triacylglycerols (TAGs) that can be used as alternatives to improve the functional characteristics of lipid systems. These low-cost industrial products are regarded as raw materials in lipid technology. They can behave as modifiers in crystallization processes, acting as preferential nuclei for ordering crystal lattices and inducing specific polymorphic patterns because of their homogeneous TAGs. Adding hard fats, such as mango, illipe, kokum, sal, shea, rambutan, palm oil, palm kernel oil, and sunflower oil, into other oils is beneficial as it increases their compatibility for uses in fat-based products, especially confectionery products. The addition of hard fats has a significant effect on the rate of crystallization, significantly decreasing the induction time for nucleation and leading to a higher hardness, and increases the thermal resistance for applications in fat-based products. The aim of this article is to review the changes in the physicochemical and thermal properties of hard fats and their mixtures obtained by fractionation, enzymatic interesterification and blending, which broaden their applicability in the food industry.
\end{abstract}

Keyword: Hard fats; Physicochemical properties; Thermal properties; Confectionery products 